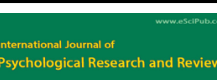

International Journal of Psychological Research and Reviews (ISSN:2639-6041)

\title{
When gambling with derivative products can become problematic: a case report of excessive trading
}

\section{Sasha Mathieu*, Isabelle Varescon \\ Université de Paris, Laboratoire de Psychopathologie et Processus de Santé, F-92100 Boulogne Billancourt, France}

\begin{abstract}
For some individuals, trading can become a problematic activity and be considered a gambling disorder due to its adverse consequences. Because few studies have been conducted to date investigating this issue, the aim of this study is to improve knowledge on this topic by presenting a case study of a participant playing the stock market. A research interview was conducted, transcribed, and analyzed using Alceste ${ }^{\circledR}$. This case study revealed three classes of meaning: the role of family in trading behavior; trading history, motives, and beliefs; and the tilt. Results shed light on the link between gambling and trading activities, and tend to support the existence of a trading behavior resembling addiction, which may be more significant when trading with high-risk derivative products due to their unique characteristics.
\end{abstract}

How to cite this article:

Keywords: problem trading; trading motives; trading-related cognitions; qualitative analysis; case study.
Sasha Mathieu, Isabelle Varescon.

${ }^{*}$ Correspondence to Author:

Sasha Mathieu

a PhD associated with the Laboratory of Psychopathology and Health Processes at the University of Paris. Among her research interests are the study of psychological processes underlying in gambling activity. She studies in particular the role of gambling type, gambling motives, cognitive distortions and emotional processes in gamblers.

When gambling with derivative products can become problematic: a case report of excessive trading. International Journal of Psychological Research and Reviews, 2021; 4:50.

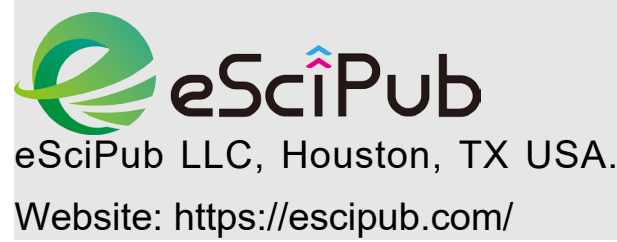




\section{Introduction}

The relationship between trading and gambling has been a question of debate for decades (Billieux et al., 2015; Grall-Bronnec et al., 2017; Granero et al., 2012; MacDougall, 1936; Murcko, 2007; Proctor, 1887). In trading, there are different types of investments and different products in which to invest, including derivative products that are particularly different from conventional financial products and relatively similar to gambling.

In the financial world, a derivative is a financial product with a value that is reliant upon the changes in prices of an underlying asset (or group of assets). The derivative requires little or no initial investment and its payment is made at a later date. In other words, the derivative product $B$ is strongly related to a financial product $A$ (the underlying asset), and the variations in the value of $B$ result from the variations in the value of $A$. The most common underlying assets are stocks, bonds, futurs, currencies, commodities, or market indexes. Thus, rather than buying or selling these types of products, as in classical trading (Guglielmo et al., 2016), investing in derivative products consists of placing stakes on the rise or fall of the financial product's value. This activity is more about betting on the direction of the fluctuation of the product value than about making a "real" investment.

Initially created to help companies protect themselves against different types of financial risks, today derivatives are products of pure speculation which one can sell (without having to own them) or purchase (without having the liquidity to pay for them). Moreover, currently anyone can open an account and invest in the stock market with a simple Internet connection, which is reminiscent of when the online gambling market opened in 2012. The advent of the Internet has therefore helped make the stock market and investments accessible to anyone (Bogan, 2008; Guglielmo et al., 2016), whereas it was once reserved for professional traders. The arrival of derivative products in the hands of private individuals democratized the financial world and trading techniques, leading some individuals to forget that investing may require the intervention of an expert or a stock market advisor, and that it is not suitable for the majority of retail investors.

With the development and access to new technologies allowing anonymous investments to take place in real time on any international stock market, trading has spread and become popular. If for the majority of individuals, this activity remains reasoned and controlled, for some it can become excessive and problematic (GrallBronnec et al., 2017; Markovic et al., 2012). Indeed, this activity, despite being socially accepted (Oliveira and Silva, 2001), involves risks such as money loss (Arthur et al., 2016; GrallBronnec et al., 2017), particularly when trading high risk products such as derivatives which can generate rapid and significant gains. Derivatives are based on a leverage effect that can either lead to an increase in winnings making them attractive, particularly to private individuals (Arthur et al., 2016; Cox et al., 2018), or an increase in losses making them risky. Indeed, derivative products were implicated in the international financial crisis between 2007 and 2011. In addition, the losses observed are generally greater for individuals who invest in options (derivatives) than for those who invest in stocks (financial product) (Bauer et al., 2009). In general, the type of investments chosen (investing in options or in stocks) seems to have an influence on the development or not of a problematic trading behavior. Just like gambling, trading seems to oscillate on a continuum from normal to pathological. Indeed, gambling and trading have similar characteristics that may lead some people to perceive the stock market as a game. The definition given to gambling could indeed correspond to that of trading (on derivatives); that is, an activity that requires an irreversible placement of money on an event of which the outcome is uncertain, in order to win money and/or material goods (Williams et al., 2017). While the stock market is generally well perceived by the public (regarding the skills, knowledge, and thought processes necessary for securing investments), derivatives, in reality, represent the opposite of these 
perceptions. The impossibility of predicting the future movement of any financial product makes trading on derivative products dependent on chance, similarly to betting. Derivatives seem to share other similarities with gambling, especially with games of luck, like their relatively short time frame, their lower expense (compared to the purchase of financial products), and their highrisk.

The literature has highlighted the existence of an overlap between problem gambling and excessive trading (Grall-Bronnec et al., 2017; Markovic et al., 2012; Turner, 2011). Indeed, trading in high-risk derivatives can, like gambling, lead the individual to develop problematic behaviors (Cox et al., 2018; Markovic et al., 2012) such as loss of control, a chase behavior, sensation seeking, and can cause symptoms of anxiety and/or depression (current or past) and the development of cognitive distortions (Granero et al., 2012; Markovic et al., 2012; Piperopoulou 2004; Turner, 2011). Nevertheless, traders with difficulty regulating their behaviors appear to be more socially responsive, have a higher level of education, suffer less personal and family-related damage from their trading activity, and are more cooperative than problem gamblers (Granero et al., 2012).

Finally, the practice of a gambling activity in addition to a trading activity seems to increase the risk of developing problematic behaviors: among a third of individuals with gambling problems, half also present a trading problem (Piperopoulou, 2004). Moreover, the rate of problem gambling was two to six times higher for high-risk traders than for low-risk traders, and was higher in day-traders (Arthur et al., 2015; Arthur and Delfabbro, 2017). High-risk traders tend to engage in a wider range of gambling activities and are more likely to be problem gamblers (Arthur et al., 2016), suggesting the existence of a continuum of risk between investment and gambling. Furthermore, Barber and colleagues (2009) had already noted that for some, gambling could be an alternative to stock market activity.

Although problem gambling is a well-recognized and widely studied entity in the literature, we currently have little information on trading and the existence of a parallel between trading and gambling. This case study aims to improve knowledge on this subject by exploring the development of problematic trading behavior as well as the shift between trading and gambling activities.

\section{Methods}

\section{Procedure}

The participant was first met in a study on gambling motives, cognitive distortions, and gamblers' emotions, that included a quantitative and a qualitative component (Barrault et al., 2018; Mathieu et al., 2018). The inclusion criteria to participate in the case study were to be at least 18 years-old, to be a fluent French speaker, to be a regular gambler (i.e. play at least once a week), and not to be in treatment for a gambling problem at the time of the study. Ethical approval was obtained from the CERES Committee (IRB number: 20162200001072) and the participant provided his written consent.

The objective of the case study is to scientifically explore a singular or complex phenomenon in its real context, and thus lead to a better understanding of the behaviors of the individual studied (Berg, 2000; Yin, 2009). The use of the case study may be justified by the motivation to study a so-called "revealing" case whose behavior has been little explored and little discussed in the literature. In this case, the participant spontaneously mentioned playing on the stock market and classified this activity as being a gambling game, thus sparking our interest in exploring his trading behavior.

\section{Research interview}

The research interview was conducted by a graduate psychologist. The interview was semistructured, based on twelve open-ended questions, to allow the participant to answer as freely as possible. A grid was developed to explore the following themes: initial trading motives and their evolution, beliefs related to the outcome of the game (winning and losing), sensations and emotions associated with the trading behavior, selfperception (through perception of trading skills), 
and the impact of the trading activity on everyday life (familial, emotional, social, professional, and financial). The research interview was carried out at Paris University and lasted 59'47 minutes.
With the agreement of the participant, the interview was recorded using a Dictaphone to transcribe his comments as accurately as possible and to analyze his speech in rigorous way.

Table 1. Participant's description: trading trajectory

The participant was 52 years-old at the time of inclusion. He comes from a modest family of civil servants, have a higher education, worked at home in the Internet sector, and was single in terms of her family situation at the time of the interview.

Attracted to the world of finance since childhood, he started trading on the stock market in 2002 as a leisure activity. In this trading activity, he saw a way to easily earn money; especially because he won the very first time he experimented investing ("in just a few hours"). Initially focused on basic financial products, he quickly oriented towards high-risk derivative products to make more significant, faster gains. He continued to bet on derivatives to make up for any losses, thinking that gains would inevitably end up happening. Whenever he won, he increased the sums of money invested, the bets, in order to win even more. He was constantly thinking about the stock market, and he obsessively followed and checked the markets on Internet, every day, even when he was at work. He also crossed certain limits that he had set for himself, like not being overdraft at the bank and always keeping a minimum of money for food shopping (especially for his family). In 2010-2011, he started to play roulette in parallel to his trading on the stock market. He had already tried poker and blackjack but these games had not attracted interest, unlike roulette. Just as for the stock market, he experienced a gain the first time he played roulette, reinforcing his belief that he could easily make gains on this game. It was partly his experiences of winnings that led him to continue these two activities, despite being initiated over two different periods. When he lost at bets on derivative products, he replaced that activity by roulette. He was trying to find ways to win (and make money), including with strategies on roulette (by placing everything on the red boxes, for example, also called the gambler's fallacy). Despite multiple losses, he had confidence in his techniques and he attributed his losses to the casino or to the banks. The participant's discourse suggested the presence of some difficulties in expressing his emotions, especially in his daily life with his family. These activities (high-risk products and roulette) seemed to have been a way for him to temporarily regulate his emotions both to appease his emotions ("when I am angry I went to the casino") as well as to provoke emotional sensations ("what surrounds the activity is not important, it's not stimulating we'll say"). A family history of gambling was also observed: as a child, his mother played a lottery game called green carpet, the winnings of which could rise up to a thousand times the initial bet.

Finally, he was no longer trading and gambling when we met him, but he continued to watch stock prices, through a system set up to bet on the stock market, leaving the possibility to come back to the "game" available at any time. No treatment was undertaken to stop this behavior or to work on his past problematic behaviors.

\section{Data analysis}

The research interview was manually transcribed then analyzed with the Alceste ${ }^{\circledR}$ software (2018 version), used to support data interpretation. The participant's data file (speech) was large enough to be submitted to Alceste ${ }^{\circledR}$ and to obtain relevant statistical data (Delavigne, 2000).

The Alceste $\AA$ software performs a quantitative lexical analysis using descendant hierarchical IJPRR: https://escipub.com/international-journal-of-psychological-research-and-reviews/ 
classification. Based on the punctuation chosen by the researcher and on the words with significant presence in the text, Alceste $\AA$ identifies context units (CUs) and the way the words are distributed within them. For this process, words are categorized into lemma, i.e. words containing the same lexical roots, represented by the symbol ' + '. This method makes it possible to extract classes of meaning, which highlight the main ideas and themes of the corpus. The decision to group and assign the words to one class or another is taken in light of the strength of the statistical link between the words and the classes created, and is estimated with a Chi-squared test. The higher the Chi2 value, the more significant the word is for the statistical structure of the class. Alceste $\AA$ also performs a hierarchical ascendant classification on the classes obtained to measure the distance between words and thus show their context of use. Extracts from the research interview, translated from French to English, will be presented in the article to support the quantitative data provided by Alceste®.

Table 2. Alceste ${ }^{\circledR}$ descending hierarchical classification $(p<.05)$

\begin{tabular}{|c|c|c|c|c|c|}
\hline \multicolumn{2}{|c|}{$\begin{array}{l}\text { Class } 1(18.80 \%) \\
\text { The role of the family in } \\
\text { the trading/gambling } \\
\text { behavior }\end{array}$} & \multicolumn{2}{|c|}{$\begin{array}{l}\text { Class } 2(58.41 \%) \\
\text { Trading history, motives, } \\
\text { beliefs }\end{array}$} & \multicolumn{2}{|c|}{$\begin{array}{l}\text { Class } 3(24.79 \%) \\
\text { and } \\
\text { Trader's tilt }\end{array}$} \\
\hline Form & $\mathrm{Chi}^{2}$ & Form & $\mathrm{Chi}^{2}$ & Form & $\mathrm{Chi}^{2}$ \\
\hline Childhood & 37 & Stock market & 9 & Feel & 30 \\
\hline Family & 32 & Casino & 8 & Limit & 19 \\
\hline Come (to) & 27 & Roulette & 8 & State & 16 \\
\hline Link (to) & 23 & Bigger & 6 & Hand over & 13 \\
\hline Mother & 23 & Luck & 6 & Overdraft & 13 \\
\hline Past & 18 & Gain & 5 & Pay (to) & 12 \\
\hline Music & 13 & Product & 5 & Put (to) & 12 \\
\hline Buy (to) & 9 & Begin (to) & 4 & Super & 9 \\
\hline Gambling & 5 & Pff & 3 & Stay (to) & 9 \\
\hline Thoroughly & 5 & Feel & 3 & Day & 9 \\
\hline Home & 5 & Works & 3 & Return & 9 \\
\hline Happy & 5 & First & 3 & Find (to) & 9 \\
\hline Remember (to) & 5 & Problem+ & 3 & Loss & 8 \\
\hline Mother-in-law & 5 & High & 2 & Bah & 6 \\
\hline Emotional & 5 & Thing & 2 & So & 6 \\
\hline Little & 3 & See (to) & 2 & Monney & 6 \\
\hline Life & 2 & Do (to) & 2 & Make up for & 5 \\
\hline \multirow[t]{8}{*}{ Head } & 2 & Win (to) & 2 & Live (to) & 3 \\
\hline & & Take (to) & 2 & Foolishness & 3 \\
\hline & & Invest & 2 & Evening & 3 \\
\hline & & Techniques & 2 & Really & 3 \\
\hline & & Cool & 1 & Say (to) & 2 \\
\hline & & Time & 1 & Possible & 1 \\
\hline & & Be able to & 1 & Lost & 1 \\
\hline & & & & Calmed & 1 \\
\hline
\end{tabular}

Note: The percentage next to the class indicates the level of the analyzed speech in this class. Note $^{2}$ : Only the words significantly present are indicated $(p<.05)$

\section{Results}

\section{Participant}

The description of the participant and his trading trajectory is presented in Table 1.
A total of 7,517 words were analyzed, corresponding to 30,792 characters excluding spaces. The textual analysis carried out by Alceste $\AA$ classified $75 \%$ of the interview into three lexical classes. The remaining $25 \%$ remained 
unclassified, probably due to the way the interview was conducted with open-ended questions, which invite the participant to answer as freely as possible.

The hierarchical descending classification analysis revealed a dendrogram containing three distinct classes of meaning (see Table 2). In addition, elements of the participant's discourse aimed at supporting the results of the textual analysis are presented in Table 3.

Table 3. Elements of participant's speech supporting the textual analysis

\begin{tabular}{|c|c|c|c|}
\hline Class & Subcategory & Themes & Illustrative quotes \\
\hline \multirow[t]{3}{*}{ Class 1} & $1^{\text {st }}$ subcategory & $\begin{array}{l}\text { Family, } \\
\text { origin and } \\
\text { history }\end{array}$ & $\begin{array}{l}\text { 'I come from a family of civil servants' } \\
\text { 'I also think that the environment we come from, the family etc., can have } \\
\text { an enormous influence' }\end{array}$ \\
\hline & $2^{\text {nd }}$ subcategory & $\begin{array}{l}\text { Material- } \\
\text { ism and } \\
\text { emotions } \\
\text { (positive) }\end{array}$ & $\begin{array}{l}\text { 'For example, I come from a civil servant family where it is "buy your house } \\
\text { and you will be quiet afterwards, well. But uh as civil servants, they earned } \\
\text { a salary always the same uh, stable uh, a small salary and, well, they have } \\
\text { their house, they are happy, etc. While I... I made a very good living.' }\end{array}$ \\
\hline & $3^{\text {rd }}$ subcategory & $\begin{array}{l}\text { Childhood } \\
\text { memories }\end{array}$ & $\begin{array}{l}\text { 'I have always been stressed since childhood because, well, this was re- } \\
\text { lated to my mother. I was always insecure, anxiety, stuff like that. And I } \\
\text { think the more we are like that, the more we are prone to take risks in life } \\
\text { for uh ... to seek self-protection. Then we make things worse in general.' } \\
\text { 'I have not had a great relationship with my mother in the past but I know } \\
\text { that these mothers can be very anxious, depressed, well, I know that uh... } \\
\text { I remember in my childhood that my mother played games. It was called } \\
\text { green carpet. Once, when she won, she jumped for joy, she was super } \\
\text { happy.' } \\
\text { 'And one day, uh, the teacher in primary school had asked, uh, "how can } \\
\text { one make money?". And I said, uh, "the stock market!" And then she con- } \\
\text { gratulated me, and she said to me "it's good that you know!", well, etc.' }\end{array}$ \\
\hline \multirow[t]{3}{*}{ Class 2} & \multirow[t]{3}{*}{$\begin{array}{l}\text { The whole cate- } \\
\text { gory }\end{array}$} & $\begin{array}{l}\text { Trading } \\
\text { trajectory }\end{array}$ & $\begin{array}{l}\text { 'On the stock market, I started on shares so something uh pretty quiet, but } \\
\text { it's after, the problem is that I started to lose big when I went to derivative } \\
\text { products, well things with very high risk where you can lose very fast and } \\
\text { big.' } \\
\text { 'Because the problem is that once I'm on the stock market, I'm focused on } \\
\text { it. I watch the stock market curves all the time, live quotes, etc., the news, } \\
\text { the news scrolling, etc.' }\end{array}$ \\
\hline & & $\begin{array}{l}\text { Trading } \\
\text { motives }\end{array}$ & $\begin{array}{l}\text { 'It was uh, I'm looking for techniques to make money. And while trying to } \\
\text { make up for screw-ups!' }\end{array}$ \\
\hline & & $\begin{array}{l}\text { Cognitive } \\
\text { distortions }\end{array}$ & $\begin{array}{l}\text { 'Fill uh almost the entire table with chips or almost all except two or three, } \\
\text { to still have a small gain. (...) There is a } 90 \% \text { chance that I win.' } \\
\text { 'Roulette uh... I was trying to find, strategies to try to, well, find the trick to } \\
\text { try to win basically!' } \\
\text { 'So I think my techniques frankly with everything I tried I would say uh } 7- \\
8,8 \text { out of } 10 \text {, even } 9 \text { out of } 10 \text { for some techniques. But I'm faced with } \\
\text { cheaters.' } \\
\text { 'Then at roulette (...) I lost about } 7,000-8,000 \text { euros in one evening. (...) I } \\
\text { started the evening and was losing all the shots. So, uh, every time I took } \\
\text { money out, I bet back on the table, etc., I bet more money, etc. And I } \\
\text { ended up with uh, at the maximum of my capacity actually. After I had no } \\
\text { money. (...) I, I was, I was really on the limit uh, the last cash that I placed: } \\
\text { there, there I won so I doubled. And after that I bet the same, times } 2 \text {, } \\
\text { times } 2 \text {. And I started to win again and again.' }\end{array}$ \\
\hline \multirow[t]{2}{*}{ Class 3} & $1^{\text {st }}$ subcategory & $\begin{array}{l}\text { Emotions, } \\
\text { sensa- } \\
\text { tions, and } \\
\text { chasing }\end{array}$ & $\begin{array}{l}\text { 'In fact it puts us in a state where we feel super bad and uh if we could } \\
\text { catch the error, well there.' } \\
\text { 'It's immediate, as soon as I lose, I give the money to try to regain it.' } \\
\text { 'And I noticed both are, are related. For example if I suffer a stock market } \\
\text { loss, I will go to the casino a few hours later to try to make up for the loss } \\
\text { in the casino.' }\end{array}$ \\
\hline & $2^{\text {nd }}$ subcategory & $\begin{array}{l}\text { Conse- } \\
\text { quences } \\
\text { of losses }\end{array}$ & $\begin{array}{l}\text { 'And after, losing } 5,000 \text { had less effect on me than the } 100 \text { euros lost in } \\
\text { the beginning actually. I became insensitive to the loss.' } \\
\text { 'Despite being at a loss, I continued.' }\end{array}$ \\
\hline
\end{tabular}


Class 1: The role of the family in the trading/gambling behavior

The temporal aspect was particularly present in this class. The ascending hierarchical classification distinguished three subcategories.

The first subcategory grouped the terms 'mother-in-law, family, to come from' (the term "come from" refers to the family history: i.e. coming from this or that type of family). It referred to the notion of family, to its origin, its history, its choices, and in this case related them to behaviors such as the (excessive) trading.

The second subcategory grouped the terms 'happy, thoroughly, emotional, music, to buy, home'. It referred to that which brings emotions, especially positive ones. For example, being able to buy their house gave the parents of the participant a sense of joy, as did the purchase of CDs. Listening to their CDs stirred up a lot of emotions for the participant when he was a teenager.

The third subcategory grouped the terms 'happy, to remember, to link, mother, gambling, early childhood, past'. It referred to childhood memories in which the participant related the environment he grew up in with his own trading and gambling behaviors later on: memories of his mother playing and feeling happy during the game and when she won, interest in the stock market having taken root in his childhood. This subcategory also highlighted how the present stems from the past.

In summary, although the words in this class refer to rather elusive speech about his childhood, what happened at the time, and his relationship to his mother, there seems to be a connection between his family history and his subsequent risk-taking behaviors.

Class 2: Trading history, motives, and beliefs

This class traced the history of the participant as a trader/gambler, hence the presence of speech marked by temporal elements such as 'begin', 'first' and 'time'. These terms referred to the beginning of his investments, then to his bets on derivatives and finally to his gambling activity (roulette). These words also referred to the first times he experienced a win on the stock market and on the roulette respectively. His life trajectory took a turn when he started betting on highrisk products, because it led to difficulties and an increased focus on the stock market. Part of his discourse was a chronological description of the activities carried out and their relation to different stages of his life/and the stages of gaming he went through. The notion of earning money was also significantly present in this class. His discourse suggested the presence of both a financial motivation (making money and then recovering lost money) and a need to show his value as an individual through money earned. Finally, this class also presented trading-related erroneous beliefs including overestimation of probabilities and skills, lack of knowledge concerning roulette and derivatives, interpretative bias, and representativeness bias.

\section{Class 3: Trader's tilt}

In gambling, the tilt can be described as a sudden influx of negative emotions such as stress or frustration which are not regulated efficiently, and which often result from a feeling of unfairness linked to the negative outcome of the game (loss). All problematic gamblers have experienced the tilt at least once. The tilt can also be triggered in trading situations, especially on high-risk products. The ascending hierarchical classification revealed two subcategories related to the tilt.

The first subcategory was about the emotional and the behavioral aspect of tilt, containing the words 'loss, make up for, mistake, evening, bah, to feel, super, bet, bet again, state (i.e. psychological state), sad'. It referred to emotions and sensations generally felt in situations of loss. The participant described how he felt when he lost bets on derivatives with difficulty: his vocabulary was rather limited (bah, uh), especially on emotional expression where feelings were negative but vague (feel, state). When the participant expressed feelings in his discourse, he mostly used the word "on", a French personal pronoun in the third person singular, which is used to described a general but not personal or individual feeling. This suggests a certain difficulty in owning and recognizing his own 
emotions. This pronoun also refers to the notion of belonging to a group, indicating in an impersonal way that other people can have these negative, difficult to live with, emotions. The loss of control in trading situations and the chase of losses, by placing money back on high-risk products or going to the casino to play roulette, was also significantly present in this class. Roulette activity, however, was motivated more by the compensation of stock exchange losses than by the game itself.

The second subcategory referred to the financial risks and the concrete consequences of the losses. It grouped together the terms: 'Find again, money, day, return (i.e. return home and a return of money), suddenly, overdraft, to pay, limit, euros, to live, to stay, really'. The financial risk he mentioned most was losing more money than he had planned to and being exposed at the bank, with an overdraft. More specific elements were also described such as chasing losses and the progressive loss of the value of money.

\section{Discussion}

To our knowledge, few research studies have investigated trading behaviors and explored the parallel between trading and gambling. Thus, the results presented in this article contribute to the existing literature and provide new findings on excessive trading, especially on high-risk derivative products, and its similarities to problem gambling. This case study sought to explore the issue of the development of problematic trading behavior as well as the shift between trading and gambling activities. Our case report sheds light on the presence of problematic trading behavior as well as on a misperception of trading activity as a game that may have participated in a shift from trading to gambling.

As a reminder, there are different types of investment (short, medium, and long term), some of which seem to share characteristics with gambling, for example the way in which derivative products represent higher risks than investments and resemble betting. The participant himself mentioned that trading is a game. According to the literature (Granero et al., 2012), derivatives known to present a very high level of risk seem to favor loss of control and subsequently, can lead to the development of a problematic behavior. This was the case for the participant encountered, who declared to have been very focused on the stock exchange, thinking about it constantly, having to increase the sums of money after a gain to earn more (and thus elicit more sensations), engaging in this activity even when emotionally perturbed by everyday difficult situations, continuing the trading activity despite losses, and sidelining his job at times for his stock market activity. The elements used to describe his activity resemble the DSM-5 pathological gambling diagnostic criteria (APA, 2013). Using these criteria could be an adequate method to diagnose excessive trading, especially because screening and diagnostic tools do not currently exist. This method is in fact preferred in some trading research (Cox et al., 2018; Grall-Bronnec et al., 2017; Markovic et al., 2012). However, it would be interesting to develop an instrument to assess the intensity of trading practice which would take into account its financial and psychological consequences, such as those reported by the participant and presented in this case study (tilt, financial risks, negative and positive feelings: psychological distress after losses and euphoria when winning or getting near a win). While the existence of a trading addiction (Billieux et al., 2015) is still debated among researchers, an addictive problem seem to exist in certain individuals gambling on the stock market.

Like gambling, trading could be seen as an activity arising from various motivations. In this case study, the choice of high-risk derivative products to trade on is not trivial as they can generate significant gains and losses. Here, the participant preferentially focused on derivatives to win money, both in the hope of a big win and with the need to regain money lost. Thus, the pursuit of the trading activity was reinforced by both winning and losing money. Moreover, in a losing situation, the participant tried to increase his chances of recovering the money lost by also playing roulette. Statman argues that the aspiration to wealth can be a motivation for lottery 
players, but also for traders (2002). Trading in order to win money also seems to resonate with other implicit motivations such as winning a victory, like winning a bet against an opponent trader. In this case study, winning also seemed to refer to the desire to obtain social recognition (especially from one's family circle) and thus be valued. Individuals who trade to attract the attention of their peers (among other reasons) are more likely to take risks and trade more frequently (Pelster, 2019).

The societal cognitive representation of trading can lead individuals interested in trading to develop a feeling of expertise in the area, for example by searching for more information, reading the economic press, following courses, etc., and could in this sense raise their self-esteem. In this case study, this so-called expertise gave the participant a sense that his techniques were good and that he had the ability to succeed and to win (money) thanks to derivative products, despite losses observed and experienced. This activity, like skill games in which strategy is involved in the outcome of the game, could lead the individual to develop cognitive distortions. In the present case study, the notion of expertise expressed by the participant is linked to an interpretative bias, an attributional belief in which gains and successes are attributed to internal factors (to oneself) and losses and failures to external factors (to others, in this case his wife, his mother-in-law, and the casinos and banks, considered cheaters). Against all expectations, the participant's losses and his recognition of the casino and banks' advantage did not bring him to revise his perceived degree of competence, suggesting he may have a low self-esteem that he is compensating for. Moreover, despite the losses, the participant tended to think that he had almost succeeded (Grall-Bronnec et al., 2017), which resembles a concept also observed among gamblers called "the near miss". The cognitive distortions highlighted in the participant's speech seem to support the fact that trading in his case may be motivated by an intrinsic desire to increase self-esteem, which was undermined in the family context and then during the game due to repeated losses. The illusion of control offers an individual the opportunity to believe in his or her ability to succeed. When events have attacked or reduced this fundamental feeling of control (Maslow, 1989), success may be necessary as a means to regain some control (Thompson et al., 1998). This may involve chasing losses until a gain is achieved, suggesting the existence of a lack of knowledge or denial of the characteristics of high-risk trading (and of roulette). When a win occurs even after many losses, the player's belief of having the skills to "sense" the direction of the stock markets could be reinforced, leading to positive and pleasant feelings about oneself.

Through his positive experiences, the participant seems to have developed the belief that trading has beneficial effects, which encourages him to pursue this activity. Indeed, the participant indicated that he persisted in the trading behavior after negatively charged everyday events or situations in order to reduce negative feelings (anger and stress) and increase his positive emotions via the excitement and stimulation that the activity provided. In this sense, the trading activity may be used for emotional regulation. Thus, chasing could improve the psychological state of the individual when effective in restoring a balance between wins and losses. However, in the event of (repeated) failure, one can imagine that symptoms of anxiety and/or depression may occur as seen in other excessive behaviors such as problem gambling (Browne, 1989).

In addition to the financial motivation, interest for derivative products may stem from the sensations and excitement that they provide (GrallBronnec et al., 2017; Grinblatt and Keloharju, 2009), particularly brought on by the high risk involved when investing in them. Indeed, the rapid and considerable value fluctuation of these products could lead individuals to experience sensations ranging from one extreme to another in quick succession. The participant described the moments he won with great enthusiasm and negative situations (family events, loss of money) with difficulty. These elements are somewhat reminiscent of the concepts of 
sensation seeking and alexithymia found in gambling, which are related to a deficit in emotion regulation. The intensification of emotions through bodily sensations could be a way for the participant to identify his feelings.

According to the literature, difficulty regulating emotions can lead to difficulties in controlling impulsive behavior (Schreiber et al., 2012) and thus to difficulties inhibiting automatic responses, poor decision making, and a preference for immediate rewards (Amlung et al., 2017; Schreiber et al., 2012). Betting on short term operations such as derivative products creates the possibility to make a big win quickly, which medium and long-term investments do not allow. Derivatives are particularly attractive for this reason. However, understanding or ignoring their capacity to cause significant losses could lead to loss of control (tilt) and chase of losses; as in this case report where a certain inability to stop trading was present. While the tilt experienced by the participant seemed to reinforce the belief that he was unable to stop trading, he nevertheless reported that he had stopped betting money on derivatives and playing roulette at the time of the interview. However, he still followed daily economic and stock market information. This behavior gives him the possibility to return to the game at any time, supporting the idea that there is a continuum between normal and pathological. Acquiring skills in the regulation of emotions reduces impulsive behaviors (Schreiber et al., 2012; Weiss et al., 2012) and appears to be a protective factor against the tilt (Laakasuo et al., 2014; Palomaki et al., 2013).

However, this study has several limitations. Firstly, it was a case study based on a research interview, which prevents the generalization of observations to all derivative traders. In addition, results rely on speech analysis, and not on validated conceptual models. Finally, this case study potentially represents a specific trader profile since the participant traded on high-risk products and gambled on roulette at the same time. This may have favored the perception of trading as a gambling activity. However, the literature highlights that trading when perceived as a game best predicts the use of leveraged derivatives (Cox et al., 2018).

Despite these limitations, the present study provides some information on trading behavior, which can become problematic among some individuals as was the case for the participant met, and on the shift from one activity to another. The elements mentioned by the participant may also echo concepts found in the gambling literature such as problematic behavior, motives, cognitive distortions, psychological distress, and the multi-activity behavior. Moreover, this case study does not pretend to the statistical generalization of the results obtained but it aims more at the understanding of a singular phenomenon and encourages the pursuit of experimental and qualitative research, with the study of multiple cases. Thus, the results reported in our study must be replicated on a larger and more diversified sample in terms of practices (trading and gambling activities), and studied using corpus analysis methods making it possible to "give meaning" to experience and deepen the understanding of the phenomenon being explored, such as interpretative phenomenological analysis (IPA) or grounded theorizing (Braun and Clarke, 2006). Comparing the trading activities with each other (short, medium and long term) and with gambling would make it possible to verify whether the data collected in this study are specific to derivatives or if they can be found in a wider practice of the stock market, to highlight the similarities and differences between these different practices, and to study the relationship between trading and gambling. Future studies could also focus on personality traits such as alexithymia, impulsivity, and sensation seeking, which are known to be involved in players with gambling problems (Barault and Varescon, 2013; Bonnaire et al., 2017) and are related to decision-making and delay discounting. In summary, trading activity should be investigated: i) in a larger sample of traders and particularly traders using the stock market as a game, ii) to obtain elements regarding the psychological functioning of these individuals, and iii) to explore similarities and differences between the 
traders making medium/long term investments and those making short term investments. Obtaining data on these behaviors would allow us to clarify the extent to which trading can be likened to behavioral addiction.

Acknowledgments The authors would like to express their sincere gratitude to the participant who took time to complete the questionnaires and agreed to be interviewed, and to thank Annika Dean for editorial assistance in English.

Ethics Approval The study was approved by the CERES Committee (IRB number: 20162200001072). All procedures followed were in accordance with the ethical standards of the responsible committee on human experimentation (institutional and national) and with the Helsinki Declaration of 1975 , as revised in 2000. Informed consent was obtained from the participant for inclusion in the study, and was confirmed again before the interview.

\section{Disclosure statements}

Funding sources This work was supported by the GIS "Jeu et Sociétés" under Grant (number CF UNI 001 3105). The funding had no role in any part of the study.

Competing interests The authors declare no competing interests.

Constraints on publishing The authors declare no constraints on publishing.

\section{Declaration of interest}

No potential conflict of interest was reported by the authors.

\section{Data availability statement}

The data that support the findings of this study are available from the corresponding author, $\mathrm{SM}$, upon reasonable request.

\section{References}

[1] American Psychiatric Association. 2013. Diagnostic and statistical manual of mental health disorders: DSM-5 (5th ed.). Washington DC: American Psychiatric Publishing.

[2] Amlung, M., Vedelago, L., Acker, J., Balodis, I. \& MacKillop, J. Steep delay discounting and addictive behavior: a meta - analysis of continuous associations. Addiction, 2017, 112(1):51-62. Doi: 10.1111/add. 13535

[3] Arthur, J. N. \& Delfabbro, P. Day traders in South Australia: Similarities and differences with traditional gamblers. Journal of Gambling Studies,
2017, 33(3):855-866. Doi: 10.1007/s10899-0169659-x.

[4] Arthur, J. N., Delfabbro, P. H. \& Williams, R. J. Is there a relationship between participation in gambling activities and participation in high-risk stock trading? The Journal of Gambling Business and Economics, 2015, 9(3):34-53. Doi: 10.5750/jgbe. v9i3.1034

[5] Arthur, J. N., Williams, R. J. \& Delfabbro, P. H. The conceptual and empirical relationship between gambling, investing and speculation. Journal of Behavioral Addictions, 2016, 5(4):580-591. Doi: 10.1556/2006.5.2016.084

[6] Barber, B. M., Lee, Y.-T., Liu, Y.-J. \& Odean, T. Just how much do individual investors lose by trading? Review of Financial Studies, 2009, 22(2):609632. Doi: $10.1093 /$ rfs/hhn046

[7] Barrault, S., Mathieu, S., Brunault, P. \& Varescon, I. Does gambling type moderate the links between problem gambling, emotion regulation, anxiety, depression and gambling motives. International Gambling Studies, 2018, 19(1):54-68. Doi: 10.1080/14459795.2018.1501403

[8] Barrault, S., Untas, A. \& Varescon, I. Special features of poker. International Gambling Studies, 2014, 14(3):492-504. Doi: 10.1080/14459795. 2014.968184

[9] Barrault, S. \& Varescon, I. Impulsive sensation seeking and gambling practice among a sample of online poker players: Comparison between nonpathological, problem and pathological gamblers. Personality and Individual Differences, 2013, 55(5):502-507. Doi: 10.1016/j.paid.2013.04.022

[10]Bauer, R., Cosemans, M. \& Eichholtz, P. Option trading and individual investor performance. Journal of Banking and Finance, 2009, 33(4):731-746. Doi: 10.1016/j.jbankfin.2008.11.005

[11]Bonnaire, C., Barrault, S., Aïte, A., Cassotti, M., Moutier, S. \& Varescon, I. Relationship between pathological gambling, alexithymia, and gambling type. The American Journal on Addictions, 2017, 26(2):152-160. Doi: 10.1111/ajad.12506

[12] Connecticut Council on Problem Gambling. (2011). Investing and gambling problems. Some investors may be at risk for gambling out of control in the stock market and other financial markets. http://www.ccpg.org/ articles/fm-investing.pdf.

[13] Billieux, J., Schimmenti, A., Khazaal, Y., Maurage, P. \& Heeren, A. Are we overpathologizing everyday life? A tenable blueprint for behavioral addiction research. Journal of Behavioral Addictions, 2015, 4(3):119-123. Doi: 10.1556/2006.4.2015. 009

[14] Bogan, V. Stock market participation and the internet. Journal of Financial and Quantitative Analysis, 
2008, 43(1):191-211. Doi: 10.1017/S0022109000 002799

[15] Bonnaire, C., Barrault, S., Aïte, A., Cassotti, M., Moutier, S. \& Varescon, I. Relationship between pathological gambling, alexithymia, and gambling type. The American Journal on Addictions, 2017, 26(2):152-160. Doi: 10.1111/ajad.12506

[16]Berg, B. L. 2000. Qualitative Research Methods for the Social Sciences $4 \mathrm{Ed}$. Allyn and Bacon.

[17]Braun, V., \& Clarke, V. Using thematic analysis in psychology. Qualitative Research in Psychology, 2006, 3(2):77-101. Doi: 10.1191/1478088706qp 063oa

[18] Browne, B. Going on tilt: Frequent poker players and control. Journal of Gambling Behavior, 1989, 5(1):3-21. Doi: 10.1007/BF01022134

[19] Cox, R., Kamolsareeratan, A. \& Kouwenberg, R. Gambling in the Stock Market: The Motivations behind Excessive and Speculative Trading. Network for Studies on Pension, Aging and Retirement, 2018, 1-37.

[20] Dechant, K. Show me the money: incorporating financial motives into the gambling motives questionnaire. Journal of Gambling Behavior, 2014, 30(4):949-965. Doi: 10.1007/s10899-013-9386-5

[21] Delavigne, V. (2000). Les mots du nucléaire : contribution socioterminologique à une analyse de discours. (Doctoral dissertation). Université de Rouen.

[22] Graham, B. \& Dodd, D. (1940). Security analysis. New York: McGraw-Hill.

[23] Grall-Bronnec, M., Sauvaget, A., Boutin, C., Bulteau, S., Jiménez-Murcia, S., Fernández-Aranda, F., Challet-Bouju, G. \& Caillon, J. Excessive trading, a gambling disorder in its own right? A case study on a French disordered gamblers cohort. $A d$ dictive Behaviors, 2017, 64:340-348. Doi: 10.1016/j.addbeh.2015.12.006

[24] Granero, R., Tárrega, S., Fernández-Aranda, F., Aymamí, N., Gómez-Peña, M., Moragas, L., Custal, N., Orekhova, L., Savvidou, L. G., Menchon, J. M. \& Jiménez-Murcia, S. Gambling on the stock market: an unexplored issue. Comprehensive Psychiatry, 2012, 53(6):666-673. Doi: 10.1016/j. comppsych.2011.12.004

[25] Grinblatt, M. \& Keloharju, M. Sensation seeking, overconfidence, and trading activity. Journal of $\mathrm{Fi}$ nance, 2009, 64(2):549-578. Doi: 10.1111/ j.15406261.2009.01443.x

[26] Guglielmo, R., loime, L. \& Janiri L. Is Pathological Trading an Overlooked Form of Addiction? Addiction and Health, 2016, 8(3):207-209.

[27] Laakasuo, M., Palomäki, J., \& Salmela, M. Experienced poker players are emotionally stable. Cyberpsychology, Behavior and Social Networking,
2014, 17(10):668-671. Doi: 10.1089/ cyber.2014.0147

[28] Lister, J. J., Nower, L. \& Wohl, M. J. Gambling goals predict chasing behavior during slot machine play. Addictive Behaviors, 2016, 62:129-134. Doi: 10.1016/j.addbeh.2016.06.018

[29] MacDougall, E. D. 1936. Speculation and gambling. Boston, MA: Stratford Company.

[30] Markovic, H., Nikolac, N., Tripkovic, M., Golubovic, I. H. \& Custovic, Z. Connection between addictive behavior and investing on the stock market in Croatia. Alcoholism and Psychiatry Research, 2012, 48(2):69-80.

[31] Maslow, A. 1989. Vers une psychologie de l'être. Paris, France: Fayard.

[32] Mathieu, S., Barrault, S., Brunault, P. \& Varescon, I. Gambling motives: do they explain cognitive distortions in male poker gamblers? Journal of Gambling Studies, 2018, 34(1):133-145. Doi: 10.1007/s10899-017-9700-8

[33] Murcko, T. 2007. What is the difference between gambling and investing? (available from: www.investorguide.com).

[34] Nigro, G., Ciccarelli, M. \& Cosenza, M. The illusion of handy wins: Problem gambling, chasing, and affective decision-making. Journal of Affective Disorders, 2018, 225:256-259. Doi: 10.1016/j.jad. 2017.08.010

[35] Oliveira, M. P., \& Silva, M. T. A comparison of horse-race, bingo, and video poker gamblers in Brazilian gambling settings. Journal of Gambling Studies, 2001, 17(2):137-149. Doi: 10.1023/A: 1016672630220

[36] Palomäki, J., Laakasuo, M. \& Salmela, M. 'This is just so unfair!: a qualitative analysis of loss-induced emotions and tilting in online poker. International Gambling Studies, 2013, 13(2):255-270. Doi: 10.1080/14459795.2013.780631

[37] Pelster, M. Attracting attention from peers: Excitement in social trading. Journal of Economic Behavior and Organization, 2019, 161:158-179. Doi: 10.1016/j.jebo.2019.03.010

[38] Piperopoulou, N. Stock market trading: A compulsive gambling behaviour with potential psychological and health problems. Psychiatriki, 2004, 15(3):253-260.

[39] Proctor, R. A. 1887. Gambling in shares. In R. A. Proctor (Ed.), Chance and luck (pp. 162- 190). London: Longmans, Green, and Co.

[40] Ricijas, N., Hundric, D. D. \& Huic, A. Predictors of adverse gambling related consequences among adolescent boys. Children and Youth Services Review, 2016, 67:168-176. Doi: 10.1016/ j.childyouth.2016.06.008

[41] Schreiber, L. R., Grant, J. E., \& Odlaug, B. L. Emotion regulation and impulsivity in young adults. 
Journal of Psychiatric Research, 2012, 46(5):651658. Doi: 10.1016/j.jpsychires.2012.02.005

[42] Statman, M. Lottery Players/Stock Traders. Financial Analysts Journal, 2002, 58(1):14-21. Doi: 10.2469/faj.v58.n1.2506

[43] Stewart, S. H. \& Zack, M. Development and psychometric evaluation of a three-dimensional Gambling Motives Questionnaire. Addiction, 2008, 103(7):1110-1117. Doi: $10.1111 / \mathrm{j} .1360-$ 0443.2008.02235.x

[44] Thompson, S. C., Armstrong, W. \& Thomas, C. IIlusion of control, underestimations and accuracy: a control heuristic explanation. Psychological Bulletin, 1998, 123(2):143-161. Doi: 10.1037/ 00332909.123.2.143

[45] Turner, N. E. The addictiveness of online brokerage services: A first person account. Journal of Gambling Issues, 2011, 25:113-129. Doi: 10.4309/jgi.2011.25.9

[46] Weiss, N. H., Tull, M. T., Viana, A. G., Anestis, M. D. \& Gratz, K. L. Impulsive behaviors as an emotion regulation strategy: examining associations between PTSD, emotion dysregulation, and impulsive behaviors among substance dependent inpatients. Journal of Anxiety Disorders, 2012, 26(3):453-458.

Doi: 10.1016/j.janxdis.2012.01.007

[47] Williams, R. J., Volberg, R. A., Stevens, R. M. G., Williams, L. A. \& Arthur, J. N. The Definition, Dimensionalization, and Assessment of Gambling Participation. Report prepared for the Canadian Consortium for Gambling Research. February 1, 2017.

[48] Wood, R. T. A., Gupta, R., Derevensky, J. L. \& Griffiths, M. Video game playing and gambling in adolescents: Common risk factors. Journal of Child and Adolescent Substance Abuse, 2004, 14, 77-100. Doi: 10.1300/J029v14n01_05

[49] Yin, R. K. 2009. Case Study Research, Design and Methods. $4^{\text {th }}$ Ed. London: Sage Publications. 